Çukurova Üniversitesi Mühendislik Mimarlık Fakültesi Dergisi, 33(4), ss. 225-240, Aralık 2018

Çukurova University Journal of the Faculty of Engineering and Architecture, 33(4), pp. 225-240, December 2018

\title{
Daralan ve Genişleyen Bir Kanal İçerisine Yerleştirilen Yarım Küreler Üzerinden Akış ve Isı Transferinin Sayısal Olarak Araştırılması
}

\author{
Doğan Engin ALNAK ${ }^{1}$, Koray KARABULUT ${ }^{* 2}$, Ferhat KOCA ${ }^{1}$ \\ ${ }^{1}$ Sivas Cumhuriyet Üniversitesi, Teknoloji Fakültesi, Otomotiv Mühendisliği Bölümü, Sivas \\ ${ }^{2}$ Sivas Cumhuriyet Üniversitesi, Sivas Meslek Yüksekokulu, Elektrik ve Enerji Bölümü, Sivas
}

Geliş tarihi: 16.01.2018 Kabul tarihi: 25.12.2018

\section{$\ddot{\mathbf{O} z}$}

Bu çalışmada; birbirleriyle bağlantılı daralan ve genişleyen bir kanal içerisine diziler halinde yerleştirilmiş yarım küreler üzerinden akış ve isı transferi üç boyutlu, sıkıştırılamaz, zamana bağlı, tam gelişmiş ve laminer akış için sayısal olarak incelenmiştir. Süreklilik, Navier-Stokes ve enerji denklemleri Ansys Fluent17.0 programı kullanılarak sayısal olarak çözülmüş̧ür. Çalışma akışkanı olarak hava kullanılmıştır. Havanın kanala giriş sıcaklığı ve küre yüzey sıcaklıkları sırasıyla $300 \mathrm{~K}$ ve $350 \mathrm{~K}$ 'dir. Çalışmada, yarım kürelerin kanala tekli ve çoklu diziler halinde olmak üzere toplamda 6 farklı tasarımda yerleşiminin ve birbirlerine göre yerleşim şekillerinin ısı geçişi ve basınç kaybı artışına olan etkileri farklı Reynolds sayıları için $(\mathrm{Re}=100,200,400$ ve 800) incelenmiştir. Sonuçlar, basınç kayıp katsayısının, Nusselt sayısının, çıkıştaki toplam ısı transferi miktarının, akışkan sıcaklığının ve ısıl performans katsayısının $(\phi)$ Re sayısıyla değişimi olarak sunulmuştur. Ayrıca, kanal boyunca sıcaklık, hız konturları ve kanallar arası akış için hız vektörleri dağılımları farklı Re sayıları için incelenmiştir. Sonuç olarak, en yüksek ısı transferi artışları sırasıyla tekli ve çoklu model dizilimlerinde akışkan hareketinin ve karışmanın daha iyi olduğu Model 2 ve 5 için elde edilmektedir. Çalışmada kullanılan yarı küre dizilimleri ile bilgisayar kasası gibi 1sınma problemi olan elektronik cihazların soğutma performansının artırılabileceği düşünülmektedir.

Anahtar Kelimeler: Daralan ve genişleyen kanal, Yarım küre, Isı transferi

\section{Numerical Investigation of Flow and Heat Transfer on Semi Spheres In Placed a Converging and Diverging Channel}

\begin{abstract}
In this study, flow and heat transfer are investigated numerically in the case of three dimensional, incompressible, unsteady, fully developed and laminar flow on semi spheres placed as serials in a communicating converging and diverging channel. The continuity, Navier-Stokes and energy equations are solved numerically by using Ansys Fluent-17.0 software program. Air is taken as working fluid. Inlet temperature of the air and sphere surface temperatures are $300 \mathrm{~K}$ and $350 \mathrm{~K}$, respectively. The effects of location of semi spheres to channel at 6 different designs as single and multiple serials and placement types of the spheres according to each other on the heat transfer and pressure drop enhancement for different Re
\end{abstract}

*Sorumlu yazar (Corresponding author): Koray KARABULUT,kkarabulut@cumhuriyet.edu.tr 
numbers $(\mathrm{Re}=100,200,400$ ve 800$)$ are researched. Results are presented as variation of pressure loss coefficient, Nusselt number, amount of total heat transfer, fluid temperature at outlet and thermal performance coefficient $(\phi)$ with Re number. Also, distributions of temperature, are investigated velocity contours along the channel and velocity vectors for the flow between channels for different Re numbers. As a result, the highest heat transfer increments are obtained for Models 2 and 5 where fluid motion and mixing are better in single and multiple model arrays, respectively. It is considered that cooling performance of electronic equipments having warming problem such as computer case can be increased with semi spheres serials used in study.

Keywords: Converging and diverging channel, Semi sphere, Heat transfer

\section{GİRIŞ}

Çeşitli 1S1 değiştiricilerin, nükleer reaktörlerin, güneş toplayıcıların, isıtıcıların, soğutucuların, içten yanmalı motorların, yanma odalarının, elektrik makinelerinin vb. cihazların tasarımlarında 1s1 geçişi büyük önem kazanmaktadır. Kompakt cihazların tasarımı için 1sı geçişinin en yüksek değerlere çıkarılması gerekmektedir. Günümüzde çeşitli tip 1Sı değiştirici tasarımları geliştirilmiştir. $\mathrm{Bu}$ 1S1 değiştiricilerinin yüzey geometrisine ait 1s1 transfer katsayısı ve akış özellikleri ile basınç kayıp katsayısının belirlenmesi gerekir. Isı geçişini arttırma yöntemlerinden biri sınır tabakanın sürekli yenilenmesidir. $\mathrm{Bu}$ amaçla literatürde kaydırılmış levha dizileri incelenmiş ve ısı geçişi katsayılarının arttırılabileceği gösterilmiştir.

Is1 transferi yüzey alanının artırılması ve en önemlisi akış karışım bölgesi oluşturularak 1s1 transferi katsayısının iyileştirilmesi için geliştirilen yöntemlerden biri, birbirleriyle bağlantılı daralan ve genişleyen kanallardır. Bu kanallar sayesinde birim hacimde yüzey alanı arttırılarak ve özellikle karışım bölgesi oluşturularak 1s1 geçişinde iyileştirme yapılabilir. Bu yüzeyler üzerindeki akışta 1s1 transferinin artmasıyla birlikte basınç düşüşü de artar. Bu nedenle bu yüzeylerin kullanımındaki asıl amaç, 1sı transferinde maksimum artışı sağlarken, basınç düşüşündeki artışı akış oranını minimuma indirerek elde etmektir. Esas amaç tüm sistem performansını artıracak en uygun değerlerin elde edilmesi olmalidir.

Periyodik olarak daralan genişleyen kanallar birçok araştırmacı için ilgi alanı olmuştur. Sparrow ve Prata [1] birbirleriyle bağlantısız, periyodik olarak daralan genişleyen konik kanallarda, Reynolds sayısı 100 ile 1000 arasındaki akışı ve 1sı transferini deneysel ve sayısal olarak incelemişlerdir. Çalışmada basınç kaybının düz boruya göre biraz daha fazla, Nusselt sayısının ise Prandtl sayısına bağlı olduğu gösterilmiştir. $\operatorname{Pr}<1$ için Nusselt sayısı düz borudan düşük, $\operatorname{Pr}>1$ için ise Nusselt sayısı düz boruya göre biraz daha yüksek çıkmıştır. Patankar [2], yaptığı çalışmada akış yönünde kesiti periyodik olarak değişen dikdörtgen kesitli kanallarda, tam gelişmiş akış şartlarında akış ve 1 sı transferini incelemiştir. Üniform duvar sıcaklığında hız ve sicaklık profillerinin modüllerde periyodik olarak değişmesi nedeniyle benzer olduğu tespit edilmiştir. Verilen bir duvar 1s1 akısında sıcaklık alanının periyodik olarak kendisini tekrarladığı tespit edilmiştir. Periyodik tam gelişmiş akış kavramı ve çözüm yöntemi ile bu tür 1S1 transfer mekanizmalarının ilk teorisini geliștirmiștir. Burada periyodik tam gelişmiş akıştaki Nusselt sayısının, düz kanal akışına göre çok yüksek ve Reynolds sayısının bir fonksiyonu olduğunu tespit etmiştir. Kelkar ve Patankar [3], kanatçıklı kanallarda akış ve isı transferini akışkan özelliklerini sabit ve akışı iki boyutlu ele alarak incelemişlerdir. $\mathrm{Bu}$ çalışmada, paralel iki levha kullanılmıș ve paralel levha yüzeylerine kanatçıklar yerleştirilerek akış simüle edilerek çözülmüştür. Hesaplamalar, farklı geometrik parametrelerde Reynolds sayısı, Prandtl sayısı ve kanatçık iletkenliği gibi değişkenler değiştirilerek incelenmiştir. Levha yüzeylerine kanatçıklar yerleştirildiğinde akışkan daha fazla yüzey ile temas ettiğinden ve karışarak hareket ettiğinden dolayı ısı transferi artışı gözlemlenmiştir. Ayrıca; basınç düşümündeki artışın 1sı transferinin artmasına yardımcı olduğu belirtilmiştir. 
Wang ve Vanka [4] periyodik sinüzodial kanallarda akış ve 1sı transferini sayısal olarak incelemişlerdir. Çalışmalarında bu tür kanallarda 1S1 geçişinin arttığını, ancak basınç kaybı artışının Nusselt sayısı artışına göre daha az olduğunu göstermişlerdir. Chunhua ve arkadaşları [5] ve Pankaj ve arkadaşları [6] periyodik olarak birbirleriyle bağlantılı eksenel girdap üreteçlerini deneysel olarak incelemişlerdir. Çalışmalarında girdap üreteçlerinde uygun kanat tipleri için karşılaştırmalarda bulunmuşlardır. Zhu ve arkadaşları [7], Chunhua ve arkadaşları [8] girdap üreteçlerinin 1 sı geçişine etkilerini üç boyutlu olarak sayısal yöntem kullanarak hesaplamışlardır. Girdap üreteçlerini kullanarak Nusselt sayısının kayda değer oranda artabileceği sonucuna varmışlardır. Sınır tabakanın yenilenmesi için kaydırılmış levha dizileri kanal ve levhada ısı ve kütle geçişi katsayıları için analitik ve sayısal sonuçlardan faydalanılarak genel denklemler çıkartılıp incelenmiştir ve ısı geçişi katsayılarının arttırılabileceği gösterilmiştir [9, 10]. Birbirleriyle bağlantılı daralan ve genişleyen kanallarda 1S1 transferini ilk olarak Yılmaz ve Ayhan [11] teorik ve deneysel olarak incelemişlerdir. Burada, kanallarda akışa dik yönde iyi bir karışım sağlandığından, normal kanallara göre 1sı geçişinin önemli ölçüde arttırılabileceği belirtilmiş ve yüksek Reynolds sayılarında 1 sı geçişinin daha da iyileştirileceği sonucuna varılmıştır. Erdinc ve Yılmaz [12], daralan ve genişleyen kanallarda farklı plaka açıları ve Reynolds sayıları için akışkan akışı ve 1sı transferini sayısal olarak incelemişlerdir. Daralan ve genişleyen kanalların sınır tabakasını önemli ölçüde değiştirdiğini ve Nusselt sayısının girdap oluşumu ve basınç düşüşü artışına karşın paralel plakalı kanallardan yaklaşık \%400 daha fazla olduğunu belirlemişlerdir. Xu ve arkadaşları [13], sonlu bir akış uzunluğu ile dikdörtgen yakınsak ıraksak oluk kesiti üzerinde bir laminar sınır tabakasının geliştirilmesini bir su kanalında boya görselleştirme ve parçacık görüntü hızını kullanarak deneysel olarak incelenmiştir. $\mathrm{Bu}$ çok yönlü yayılma pürüzlülüğünün üzerindeki akış topolojisi bu çalışmadan belirlenmiştir. Yakınsak rraksak olukların 1raksama çizgisinden bitişik yakınsama hattına doğru olukların üzerinde bir yayılma akışı oluşturduğu gösterilmiştir.
Birbirleriyle bağlantılı elemanlarda ısı transferinin, bağlantısız elemanlara göre çok yüksek olacağı Fuji ve arkadaşları [14] tarafından gösterilmiş ve bunlarla ilgili benzer çalışmaların sonuçları verilmiştir. Yapılan deneyler sonucunda bu tasarımın 1S1 transferini arttırmak için etkili bir yöntem olduğu gösterilmiştir. Kotcioğlu ve Bölükbaşı [15], dikdörtgen kesitli düşey bir kanala üç farklı kanatçık yerleştirerek deneyler yapmışlardır. Deney elemanlarına ait kanatçıklar, düzlem yüzey, silindirik ve hava akış yönüne göre açı yaparak daralan ve genişleyen kanatçıklar şeklindedir. Gruplar halinde periyodik olarak yerleştirilen kanatçıkların özellikle daralan ve genişleyen kanatçıklarda sınır tabakanın da periyodik olarak yenilenmesinden dolayı 1sı geçiş katsayısının iyileştiği sonucuna varılmıştır. Karabulut ve arkadaşları [16] birbiriyle bağlantılı daralan ve genişleyen bir kanala yerleştirilmiş 32 adet yarım kürenin çoklu diziler halinde yerleşiminin ve birbirlerine göre yerleşim şekillerinin 1Sı transferi ve basınç kaybı artışına olan etkilerini üç boyutlu ve sayısal olarak incelemişlerdir. Yarım kürelerin çoklu diziler halinde yerleşimi durumunda küre yerleşim şekillerinin öneminin büyük olduğunu ve özellikle kanallar arası akışkan dolaşımının ve karışmanın iyi olduğu modellerde daha yüksek ısı transferi artışları elde edilirken basınç düşüşünün de buna paralel olarak arttığını gözlemlemişlerdir.

Literatürde belirtilen çalışmalar göz önüne alındığında, genellikle kaydırılmış levha dizileriyle oluşturulan kanallara rastlanırken bu çalışmada konstrüksiyonları basit, hareketli parçaların olmadığı, dolayısıyla maliyetlerinin düşük olacağ1 ve parçaların ardında karışmanın daha iyi sağlanması nedeniyle literatürden farklı olarak özgün geometri ve dizilimlerine sahip yarım kürelerin oluşturduğu tekli ve çoklu daralan ve genişleyen kanal tipleri araştırılmıştır. Özellikle bilgisayar kasası gibi elektronik ekipmanların fazla ısınması sonucu sistemdeki isıl gerilmelerin artması ve mekanik arızalar sebebiyle olabilecek istenmeyen sonuçların önlenmesi bakımından daha yüksek 1S1 transfer oranları elde edilerek soğutmanın daha etkin olabilmesi için düz kanala yerleştirilen yarım küre şeklindeki bu geometrilerle 
oluşturulan daralan ve genişleyen kanalların 1sı transfer performans özelliklerini ve basınç düşüşünü araştırmak amacıyla sunulan bu çalışmada; tekli dizilimde 8 adet ve çoklu dizilimde her sirada 8 adet olmak üzere 4 siralı toplamda 32 adet yarım kürenin her iki dizilim tipinde birbirlerine göre farklı şekillerde yerleşiminin daralan ve genişleyen kanalların ısı transferi, basınç düşüşü ve akış yapısı üzerindeki etkileri incelenmiştir. Çalışmada ayrıca, kanal boyunca sıcaklık, hız konturu ve hız vektörü dağılımları incelenmiş ve yarım kürelerin daralan ve genişleyen kanallar arası sıcaklık, hız ve akış özellikleri üzerindeki etkileri de değerlendirilmiştir. Bununla birlikte, farklı Reynolds sayılarının Nusselt sayısı üzerindeki etkisi de incelenmiştir. Hesaplamalar, FLUENT paket programı kullanılarak yapılmıştır. Sonuçlar, tekli ve çoklu dizilimli 6 farklı modelin birbirleri arasında karşılaştırılmasıyla basınç düşüş katsayısı, kanal çıkışındaki akışkan sıcaklık değişimleri, toplam 1sı transferi miktarı, Nusselt sayısı değişimleri ve ayrıca sıcaklık, hız konturları ve hız vektörleri dağılımları olarak sunulmuştur.

\section{SAYISAL YÖNTEM}

Sayısal çalışma üç boyutlu, laminer, sıkıştırılamaz, 1sı transferi içeren ve daimi olmayan akışa ait denklemleri çözmek için sonlu hacimler yöntemi (FLUENT programı) kullanılmıştır.

Sonlu hacimler yöntemi, çözülecek geometriyi parçalara bölerek bu parçaların her biri için çözüm yapma ve daha sonra bu çözümleri birleştirerek problemin genel çözümünü bulma esasına dayanır. Sonlu hacimler yöntemi, korunum denklemlerini sayısal olarak çözümlenebilen cebirsel denklem sistemlerine dönüştürmek için kontrol hacim esaslı bir teknik kullanır. Bu teknik her bir kontrol hacmi için korunum denklemlerinin integrasyonunun alınması sonucunda, değişkenler için kontrol hacmini sağlayan ayrık eşitliklerin elde edilmesini içerir. Ayrık eşitliklerin doğrusallaştırılması ile elde edilen, doğrusal denklem sistemlerinin iterasyona bağlı çözümü ile hız, basınç ve sıcaklık gibi değişkenler verilen yakınsaklık ölçüsünü sağlayıncaya kadar güncellenir. Hazırlanabilecek en uygun ağ yapısı için hız, basınç ve sıcaklık değişiminin fazla olduğu bölgelerde daha sık ağ yapısı oluşturulmalıdır. Bu nedenle, yarım kürelerin yüzeyleri en sık ağ yapısının olduğu kısımlardır ve diğer bölgelerde daha seyrek ağ yapısı tercih edilmiştir. Sayısal modelde, toplamda 752026 adet elemandan oluşan dikdörtgensel ve altıgensel ağ yapısı kullanılmış ve ayrıca sonuçların ağ yapısından bağımsızlığı da sağlanmıştır. Sayısal çözümleme, yakınsama kriterleri süreklilik ve momentum denklemleri için $10^{-6}$ ve enerji denklemi için $10^{-7}$ alınarak yapılmıştır. Ayrıca Şekil 1'de modele uygulanan ağ yapısı gösterilmiştir.

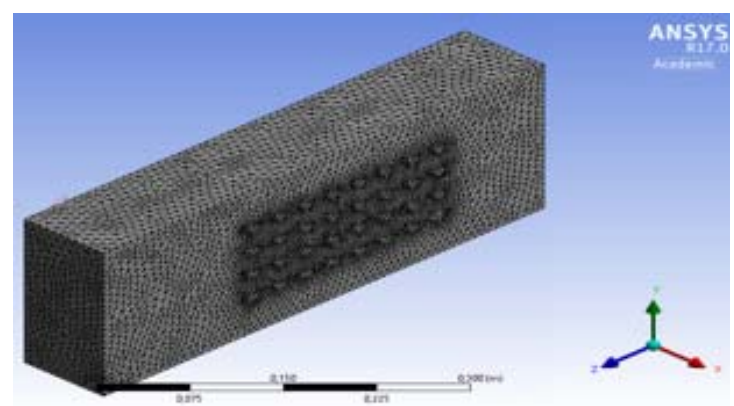

Şekil 1. Modele uygulanan ağ yapısı

$\begin{array}{ll}\text { Kanal şekli } & : \text { Dikdörtgensel } \\ \text { Kanal yüksekliği }(\mathrm{H}) & : 120 \mathrm{~mm} \\ \text { Kanal genişliği }(\mathrm{L}) & : 243 \mathrm{~mm} \\ \text { Kanal elemanı şekli } & : \text { Yarım küre } \\ \text { Kanal elemanı açısı }(\Phi) & : 20^{\circ} \\ \text { Kanal elemanı çapı }(\mathrm{D}) & : 20 \mathrm{~mm} \\ \text { Kanal elemanları arası } & \\ \text { uzaklık (l) } & : 30 \mathrm{~mm} \\ \text { Reynolds sayısı } & : 100,200,400,800 \\ \text { Akışkan sıcaklığı }\left(\mathrm{T}_{\mathrm{c}}\right) & : 300 \mathrm{~K} \\ \text { Küre yüzey sıcaklığı }\left(\mathrm{T}_{\mathrm{cf}}\right) & : 350 \mathrm{~K}\end{array}$

Bu çalışma, belirtilen kabuller altında yapılmıştır:

i) Akış üç boyutlu, zamana bağlı ve laminerdir;

ii) Kullanılan akışkan sıkıştırılamaz ve havadır;

iii) Kanal ve kanal elemanı (yarım küre) malzemesi olarak alüminyum kullanılmıştır; 
iv) Akışkanın $1 s ı l$ özellikleri sabittir;

v) Hem akışkan hem de katı malzeme için $1 s ı$ üretimi söz konusu değildir.

Geometri boyunca akış ve 1 s1 transferinin çözümlemesi, zamana bağlı olarak kütlenin (süreklilik denklemi), momentumun ve enerjinin korunumu kanunlarından elde edilen kısmi türevli denklemlerin çözümlenmesi esasına dayanır, [17]. Ayrıca, sayısal çözümde ortalama olarak $140 \mathrm{~s}$ (14000 adım ve $0,01 \mathrm{~s}$ zaman adımında) sonra belirtilen yakınsama kriterlerine ulaşıldığından bu zaman süreci bitiminde elde edilen sonuçlar sunulmuştur. Zamandan bağımsız olarak elde edilen sonuçlarla 0,01 s'lik adımda toplamda 140 s'de zamana bağlı elde edilen sonuçlar kıyaslanmış ve birbirleriyle uyum içerisinde oldukları görülmüş̧ür. Bu nedenle, 0,01 s'lik zaman adımının yeterli olduğu tespit edilmiştir.

Süreklilik denklemi Eşitlik 1'de

$\frac{\partial u}{\partial x}+\frac{\partial v}{\partial y}+\frac{\partial w}{\partial z}=0$

Momentum

x momentum denklemi Eşitlik 2'de

$$
\begin{gathered}
\rho\left(\frac{\partial u}{\partial t}+u \frac{\partial u}{\partial x}+v \frac{\partial u}{\partial y}+w \frac{\partial u}{\partial z}\right)= \\
-\frac{\partial p}{\partial x}+\mu\left(\frac{\partial^{2} u}{\partial x^{2}}+\frac{\partial^{2} u}{\partial y^{2}}+\frac{\partial^{2} u}{\partial z^{2}}\right)
\end{gathered}
$$

y momentum denklemi Eşitlik 3'de

$$
\begin{aligned}
& \rho\left(\frac{\partial v}{\partial t}+u \frac{\partial v}{\partial x}+v \frac{\partial v}{\partial y}+w \frac{\partial v}{\partial z}\right)= \\
& -\frac{\partial p}{\partial y}+\mu\left(\frac{\partial^{2} v}{\partial x^{2}}+\frac{\partial^{2} v}{\partial y^{2}}+\frac{\partial^{2} v}{\partial z^{2}}\right)
\end{aligned}
$$

z momentum denklemi Eşitlik 4'te

$$
\begin{aligned}
& \rho\left(\frac{\partial w}{\partial t}+u \frac{\partial w}{\partial x}+v \frac{\partial w}{\partial y}+w \frac{\partial w}{\partial z}\right)= \\
& -\frac{\partial p}{\partial z}+\mu\left(\frac{\partial^{2} w}{\partial x^{2}}+\frac{\partial^{2} w}{\partial y^{2}}+\frac{\partial^{2} w}{\partial z^{2}}\right)
\end{aligned}
$$

Enerji denklemi Eşitlik 5'de

$$
\frac{\partial T}{\partial t}+u \frac{\partial T}{\partial x}+v \frac{\partial T}{\partial y}+w \frac{\partial T}{\partial z}=
$$

$\left(\frac{k}{\rho c_{p}}\right)\left(\frac{\partial^{2} T}{\partial x^{2}}+\frac{\partial^{2} T}{\partial y^{2}}+\frac{\partial^{2} T}{\partial z^{2}}\right)$

Bu denklemlerde, $\rho$ yoğunluk, $\mu$ dinamik viskozite, $p$ basınç, $k$ isıl iletkenlik, $T$ sıcaklık, $c_{p}$ özgül ısı ve $u, v, w$ ise sırasıyla $\mathrm{x}, \mathrm{y}$ ve $\mathrm{z}$ yönlerindeki hızlardır.

Reynolds sayısı Eşitlik 6'da

$R e=\frac{V_{\infty} \cdot D_{h}}{v}$

Burada, $D_{h}$ kanalın hidrolik çapıdır. (Eşitlik 7)

$D_{h}=\frac{4 A_{c}}{P}=\frac{4(H \cdot W)}{2(H+W)}$

Ac kanalın kesit alanı, P ise kanalın çevre uzunluğu, $\mathrm{H}$ ve $\mathrm{W}$ ise sırasıyla kanalın yüksekliği ve enidir.

Sınır şartı ve Nusselt sayısı Eşitlik 8 verilmiştir.

$-k\left(\frac{d T}{d n}\right)_{\text {yïzey }}=h\left(T_{s}-T_{\infty}\right)$ ve $N u=\frac{h \cdot D_{h}}{k}$

$h$ yüzey ısı taşınım katsayısıdır.

Basınç düşüşü Eşitlik 9 ile hesaplanabilir.

$$
\Delta P_{L}=f \cdot \frac{L}{D_{h}} \cdot \frac{\rho \cdot V_{m}^{2}}{2}
$$

$\Delta \mathrm{P}_{\mathrm{L}}$ akış yönünde kanaldaki basınç düşüşü, $\mathrm{f}$ ise basınç kayıp katsayısı (sürtünme faktörüdür). 
Daralan ve Genişleyen Bir Kanal İçerisine Yerleştirilen Yarım Küreler Üzerinden Akış ve Isı Transferinin Sayısal Olarak Araştırılması

Paralel plakalar arası f, sürtünme faktörü (basınç kayıp katsayısı) analitik olarak Eşitlik 10 ile hesaplanabilir.

$$
f=\frac{96}{\operatorname{Re}}
$$

Isıl performans katsayısı Eşitlik 11'de verilmiştir.

$$
\phi=N u / f
$$

\section{GEOMETRİK MODEL}

Daralan ve genişleyen kanal içerisine tekli ve çoklu diziler halinde yerleştirilen yarım kürelerin akış ve sıcaklık alanlarını sayısal olarak çözmek amacıyla Şekil 2'de gösterildiği gibi bir dikdörtgen kanal ve değişik durumlarda yarım kürelerden oluşan 6 farklı model kullanılmıştır. Burada, akış kanalın içine doğru olmaktadır. Şekil 3'de geometrilere ait sınır şartları gösterilmektedir. Alt, üst ve yan çeperler katı yüzey olup duvar olarak tanımlanırken, kanalın sol tarafı hız girişi, sağ tarafı ise basınç çıkışı olarak tanımlanmıştır. Üst ve alt çeperlerde kaymama şartı da göz önüne alınarak sınır şartları duvarlarda; $\mathrm{u}=\mathrm{v}=\mathrm{w}=0$; girişte hız; $\mathrm{V}_{\text {giriş }}$ ve akışkan (hava) sıcaklığ $1 \mathrm{~T}_{\mathrm{c}}$; küreler üzerinde; $\mathrm{u}=\mathrm{v}=\mathrm{w}=0 ; \mathrm{T}_{\mathrm{cf}}$ ve kanal çıkışında; $P_{\text {cf }}$ olarak alınmıştır. Aynı zamanda hesaplamayı kolaylaştırmak amacıyla kanal ortadan ikiye bölünmüş olup simetri sınır şartı geçerlidir (Şekil 3). Yarım kürelerin üzeri $350 \mathrm{~K}$ 'e kadar 1sıtılmaktadır. Kanalın giriş kısmından ortalama sıcaklığ $300 \mathrm{~K}$ olan bir akışkan (hava) girmekte ve kanal çıkışından çalışma alanını terk etmektedir. Giriş hızları için Reynolds sayıları sırasıyla, $\mathrm{Re}=100,200,400$ ve 800'dür. Çalışmada düşük Re sayıları ile laminer akış şartları oluşturularak 1sı transferinin artırılması hedeflenmiştir. Böylece, soğutmada kullanılan fan gücünde artışa gerek duyulmaksızın küreler arası akışkan karışmasının da sağlanarak 1sı geçişinde kazanım elde edilmesi hedeflenmiştir. Küreler, kanal giriş ve çıkışından $15 \mathrm{~mm}$ ve alt ve üst yüzeylerden yine $15 \mathrm{~mm}$ uzağa yerleştirilmişlerdir. Tekli modellerde 8 adet ve çoklu modellerde ise 32 adet yarım küre bulunmaktadır. Model boyutları ayrıca Model 6 için Şekil 2'de gösterilmiştir.
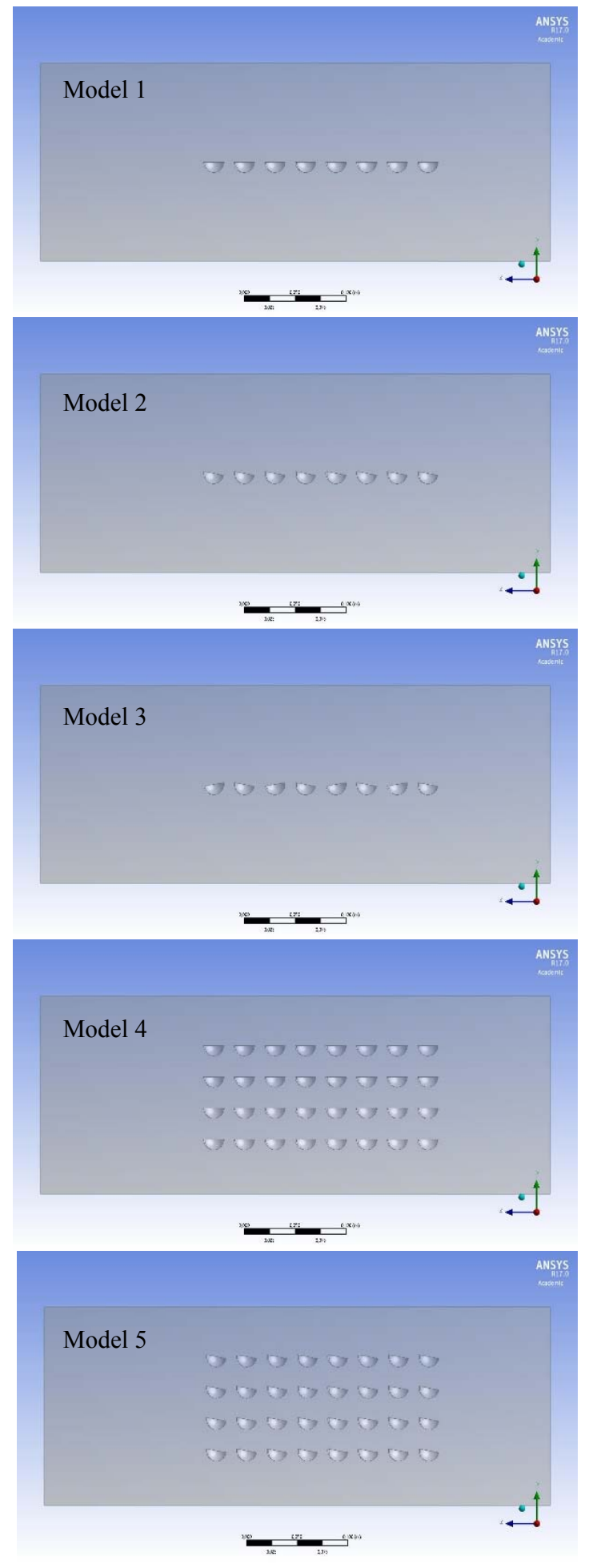

Ç.Ü. Müh. Mim. Fak. Dergisi, 33(4), Aralı 2018 

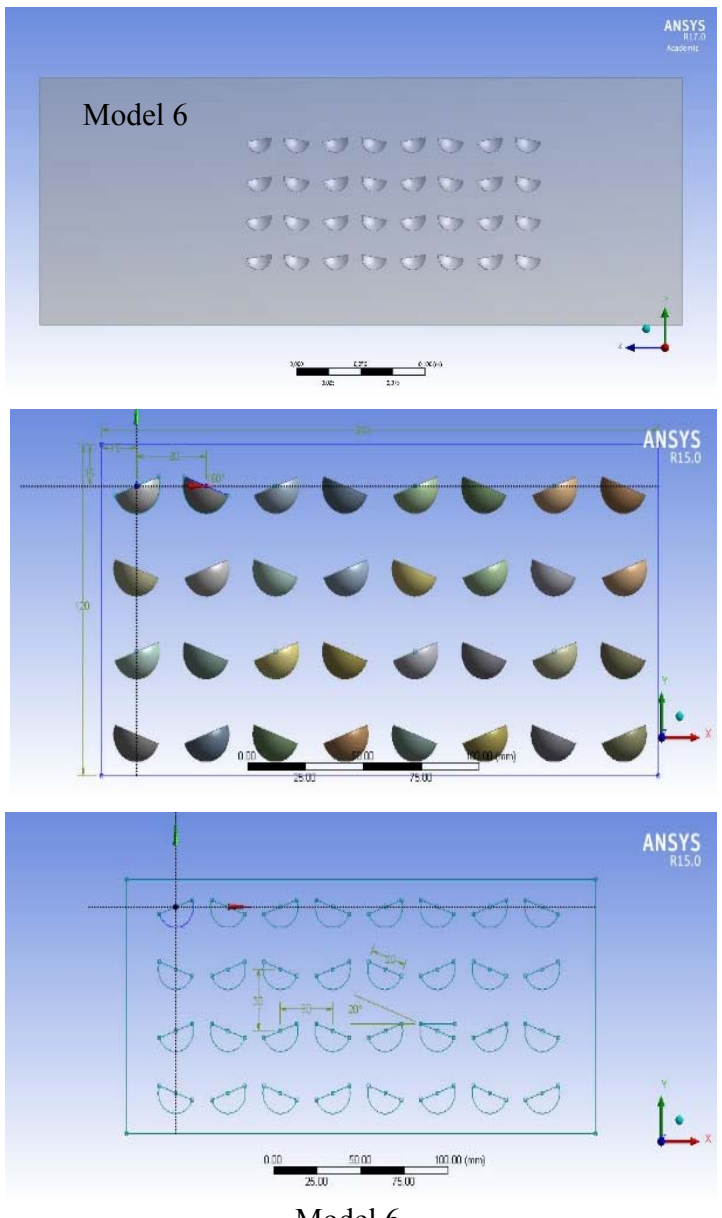

Model 6

Şekil 2. Sayısal hesaplamada kullanılan modeller ve boyutları

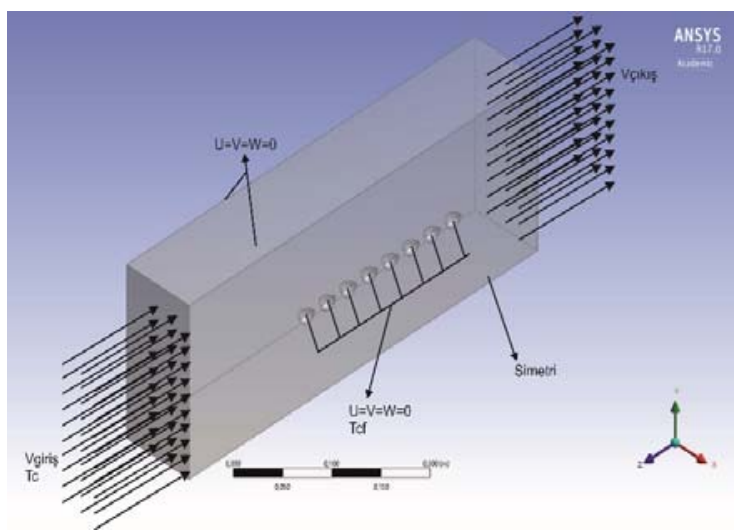

Şekil 3. Sayısal hesaplamada kullanılan sınır şartları

\section{BULGULAR VE DEĞERLENDIRME}

Paralel levha için sunulan sayısal çalışmanın f-sürtünme faktörünün Re sayısı ile değişiminin sonuçları, analitik (Eşitlik 10) ve Erdinç [18]'den elde edilen sayısal sonuçlarla karşılaştırılması Şekil 4'de gösterilmektedir. Sonuçların birbirleriyle oldukça uyumlu oldukları görülmüş ve bu nedenle sayısal çalışmanın doğru ve kabul edilebilir olduğu sonucuna varılmıştır. Ayrıca, f-sürtünme faktörünün karşılaștırmalı sonuçları Çizelge 1'de de ayrıntılı olarak gösterilmektedir.

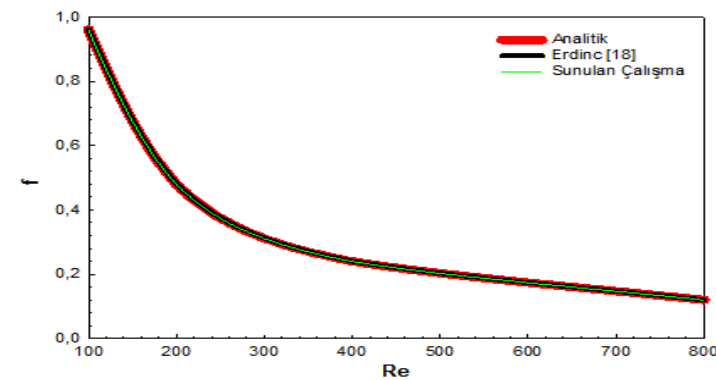

Şekil 4. f için elde edilen sonuçların karşıllaştırılması

Çizelge 1. f için elde edilen değerlerin ayrıntılı gösterimi

\begin{tabular}{|c|c|c|c|}
\hline Re & f (Analitik) & f (Erdinc, [18]) & $\begin{array}{c}\text { f (Sunulan } \\
\text { Çalışma) }\end{array}$ \\
\hline 100 & 0,96 & 0,960159 & 0,9579 \\
\hline 200 & 0,48 & 0,481034 & 0,4789 \\
\hline 400 & 0,24 & 0,240616 & 0,2394 \\
\hline 800 & 0,12 & 0,120082 & 0,1197 \\
\hline
\end{tabular}

Çizelge 2. Ağ sayısının Nusselt sayısı değişimine etkisi

\begin{tabular}{|c|c|c|c|c|}
\hline \multirow{2}{*}{$\begin{array}{l}\text { A } \breve{g} \\
\text { adı }\end{array}$} & \multirow{2}{*}{$\begin{array}{c}\text { A } \breve{g} \\
\text { elemanı } \\
\text { sayısı }\end{array}$} & \multicolumn{3}{|c|}{ Ortalama Nusselt sayısı } \\
\hline & & $\mathbf{R e}=\mathbf{1 0 0}$ & $\mathbf{R e}=\mathbf{2 0 0}$ & $\operatorname{Re}=400$ \\
\hline G1 & 238524 & 10,0112 & 11,7544 & 13,7442 \\
\hline $\mathrm{G} 2$ & 403547 & 10,8134 & 12,3543 & 14,3475 \\
\hline G3 & 752026 & 10,9286 & 12,4251 & 14,4350 \\
\hline G4 & 925405 & 10,9278 & 12,4249 & 14,4349 \\
\hline
\end{tabular}

Sunulan çalıșmanın sonuçlarının ağ sayısından olan bağımsızlığını belirlemek için dikdörtgensel bir kanalda Model 1 için ağ elemanı sayısı değiştirilerek ortalama Nusselt sayısının Reynolds sayısıyla değişiminin sonuçları incelenmiştir (Çizelge 2). 
İnceleme sonucunda, kanal kesitinde 752026 adet elemanın olduğu ağ yapısının yeterli olduğu sonucuna varılmıştır.

Şekil 5'de Model 1, 2 ve 3 olmak üzere tek siralı halde düzenlenmiş 8 farklı yarım kürenin birbirlerine göre farklı şekilde dizilmesiyle oluşan modeller için f-sürtünme faktörünün (basınç kayıp katsayısı) Re sayısı ile değişimi gösterilmektedir. Yarım küreler arasında kürelerin alt ve üst taraflarından gelen akışkanların karışmasının az olduğu Model 1 için sürtünme faktörü değeri en az iken karışma oranının artmaya başladığ $\breve{1}_{\text {Model }} 2$ ve 3 'de ise sürtünme faktörü ve buna bağlı olarak da basınç kaybı artmaktadır. $R e=200$ 'de Model 1 için f değeri 1,1591 iken, Model 2 ve 3 için sırasıyla 1,2635 ve 1,2697 olmaktadır. Ayrıca, Reynolds sayısının artmasıyla sürtünme faktörünün azaldığı Şekil 5'de görülebilmektedir.

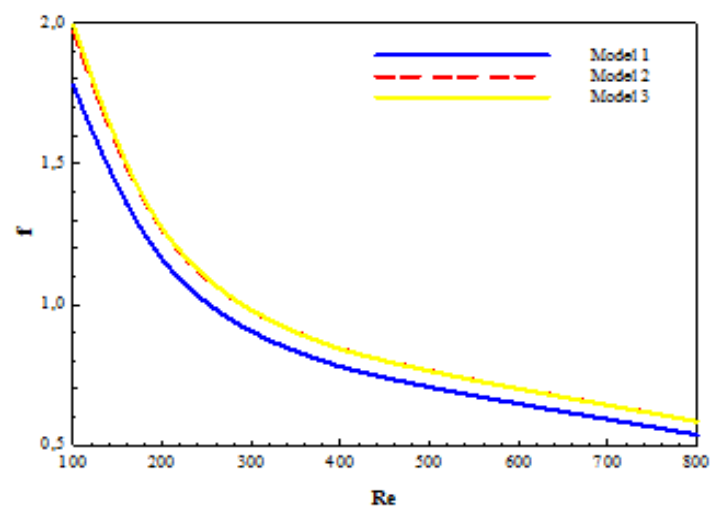

Şekil 5. Basınç kayıp katsayısının (f-sürtünme faktörü) Reynolds sayısı ile değişimi

Model 1, 2 ve 3'e ait akışkanın kanaldan çıkış sıcaklıklarının Reynolds sayısı ile değişimi Şekil 6'da gösterilmektedir. En yüksek basınç kayıp katsayısının Model 3' de elde edilmesi (Şekil 5) akışkanın yarım küreler arasındaki kanallardan geçişinin daha az olması nedeniyledir. Bunun sonucunda, akışkanın kanallar arasından geçişinin daha rahat sağlandığı Model 2'de Model 3'e göre daha yüksek çıkış sıcaklık değerleri elde edilebilmektedir (Şekil 6). Re=400 için Model 2'de çıkış sıcaklık değeri 315,47 K iken Model 3'de $314,96 \mathrm{~K}$ olmaktadır. En düşük çıkış sıcaklığının ise karıșma miktarının daha az olduğu Model 1'de elde edildiği Şekil 6'dan rahatlıkla görülebilmektedir.
Aynı Reynolds sayısında $(\mathrm{Re}=400)$ çıkış sıcaklığı 314,46 K' dir. Bununla birlikte, Reynolds sayısının artışıyla akışkan hızı arttığından iletimle 1s1 transferi direnci artmakta ve bu nedenle çıkış sıcaklık değerleri azalmaktadır.

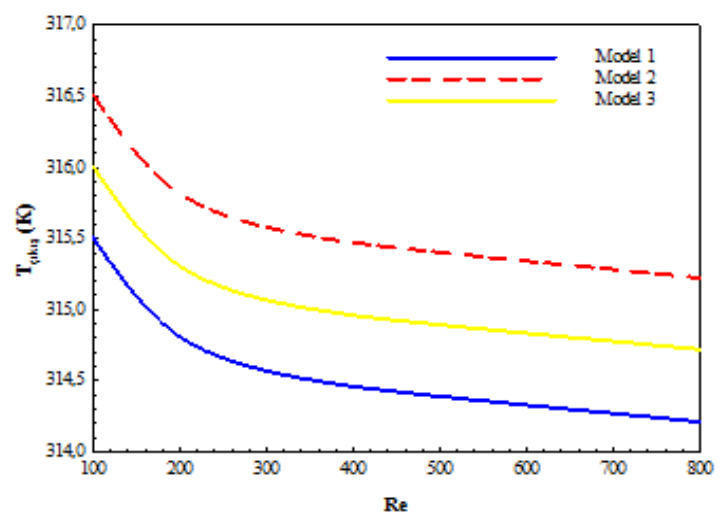

Şekil 6. Akışkan çıkış sıcaklığının Reynolds sayısı ile değişimi

Kanallar arası akışkan hareketinin daha rahat olduğu ve karıșma oranının da artmasıyla sıcaklık değişimininin de artması sonucu taşınımla 1s1 transferinin bir göstergesi olan Nusselt sayısının arttığı Şekil 7'den rahatlıkla görülebilmektedir. Bununla birlikte, kanalda ortalama olarak en yüksek Nu sayısı değeri Model 2 için elde edilirken, en düşük değer Model 1 için elde edilmektedir. $\mathrm{Re}=800$ değeri için $\mathrm{Nu}$ sayısı değerleri incelendiğinde Model 2 için $\mathrm{Nu}=18,3497$ iken Model 1 için 17,2496 değerleri elde edilmektedir.

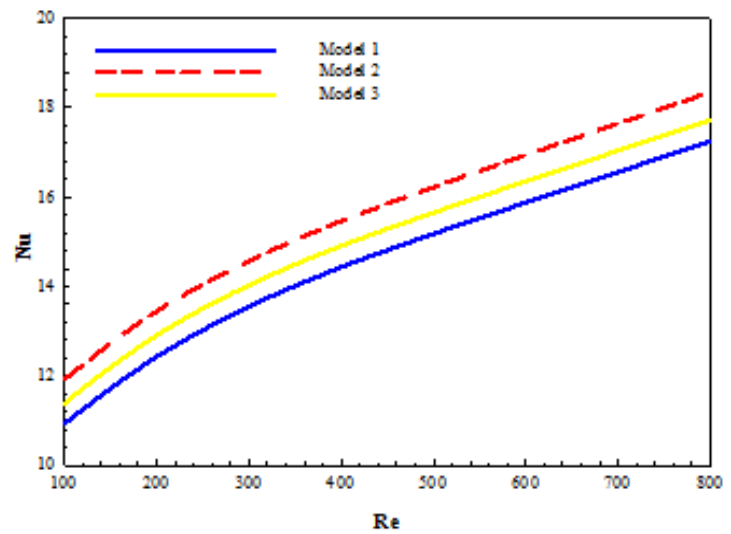

Şekil 7. Kanal boyunca ortalama Nusselt sayısının Reynolds sayısı ile değişimi 
Çıkıştaki akışkan sıcaklığının artması Şekil 8'de gösterildiği gibi Model 2'de akışkana olan 1S1 transferi miktarının daha fazla olmasından kaynaklanmaktadır. Böylece küre yüzey sıcaklıkları azalırken, akışkan sıcaklığı ise artmaktadır. Reynolds sayısının 200 olduğu değer için Model 1'de çıkıştaki 1sı akısı değeri 170,9 W/m² iken Model 2'de bu değer 176,0618 W/m² değerine çıkmaktadır. Model 3'de ise bu değer $173 \mathrm{~W} / \mathrm{m}^{2}$, dir.

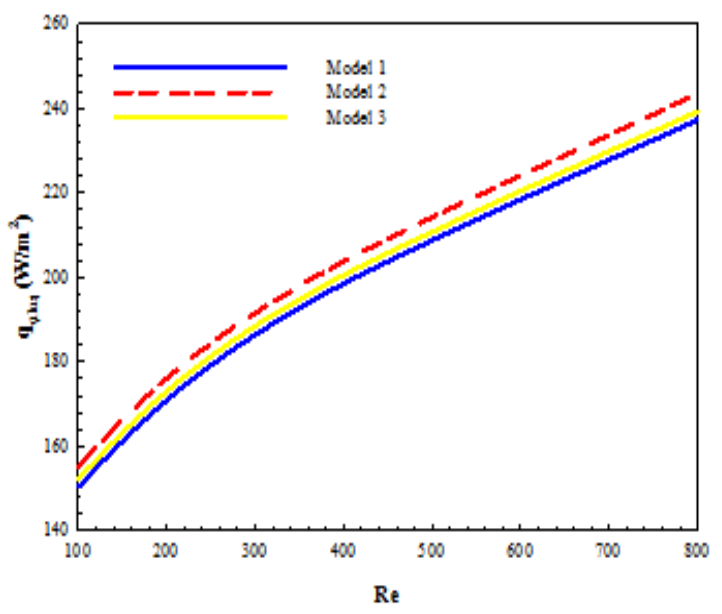

Şekil 8. Kanal çıkışında ısı miktarının Reynolds sayısı ile değişimi

Şekil 9' da 8'erli diziler halinde 4 sıralı toplamda 32 adet yarım kürenin farklı şekilde dizilmesiyle oluşturulan daralan genişleyen 3 farklı kanal (Model 4, 5 ve 6) için basınç kayıp katsayısının Re sayısı ile değişimi gösterilmektedir. Model 5 ve 6 için elde edilen kayıp katsayısı değerleri birbirine çok yakın olmakla birlikte küreler arasında akışkanın geçişinin daha güç olduğu Model 6'da daha fazla kayıp katsayısı değerleri elde edilmektedir. $\mathrm{Bu}$ değer, Model 5 için $\mathrm{Re}=200$ 'de 1,5385 iken Model 6'da 1,5403'tür. Bununla birlikte, en düşük f değeri 1,4629 ile Model 1 için elde edilmiştir. Ayrıca, laminar akışta sürtünme faktörü $\mathrm{Re}$ sayısının bir fonksiyonudur ve $\mathrm{Re}$ sayısının artışıyla sürtünme faktörü azalmaktadır.

Şekil 10'da akışkanın kanaldan çıkış sıcaklığının Model 4, 5 ve 6 için Re sayısı ile değişimi gösterilmektedir. Model 5'de 1sı transfer yüzey alanının artırılmasının yanı sıra Model 4 ve 6'ya göre akışkanın kanallar arasından geçişi de artırıldığından daha yüksek akışkan çıkış sıcaklık değerine ulaşılmaktadır. $\mathrm{Bu}$ değer $\mathrm{Re}=800$ 'de 324,4898 K değerine ulaşmaktadır. Aynı zamanda, Şekil 10'da da görülebildiği gibi Re sayısının artmasıyla iletim (kondüksiyon) direnci artmakta, taşınım (konveksiyon) direnci ise azalmaktadır. Bu nedenle, Reynolds sayısının artması akışkanın kanaldan çıkış sıcaklığının azalmasına neden olmaktadir.

Bununla birlikte, Şekil 11'de görüldüğü gibi akışkan hızının artırılması (Re'ın artışı) taşınımla 1S1 transferini artırdığından $\mathrm{Nu}$ sayısı da artmaktadır. En yüksek $\mathrm{Nu}$ sayısı değerine yine kanallar arası akışkan geçişinin ve karışmanın daha iyi olduğu Model 5'de ( $\mathrm{Re}=800$ için $\mathrm{Nu}=53,7034)$ ulaşılmaktadır. Model 1 için aynı Re sayısında $(\mathrm{Re}=800) \mathrm{Nu}=52,4197$ 'dir. Şekil 12'de de akışkana olan ısı transferi miktarının çıkıştaki değerinin Re sayısı ile değişimi gösterilmektedir. Re sayısının artışı 1sı transferi miktarını artırırken, en yüksek 1sı transferi miktarına Model 5 için ulaşılmaktadır ki bu değer $\mathrm{Re}=800$ için 416,9964 W/m²' dir. Aynı Re sayısında çıkıştaki ısı akısı değeri Model 1 için $410,1539 \mathrm{~W} / \mathrm{m}^{2}$, dir.

Şekil 13 a) ve b)'de isıl performans katsayısının $(\mathrm{Nu} / \mathrm{f}) \mathrm{Re}$ sayısı ile değişimi gösterilmektedir. Model 2, 1S1 transferi bakımından değerlendirildiğinde karşılaştırıldığı üç model içinde (Model 1, 2 ve 3) en yüksek 1sı transfer katsayısına sahip olan modeldir. Benzer olarak, Model 5'de araştırıldığı çoklu modeller içinde 1sı transferi bakımından en iyi modeldir. Ancak, Şekil 13 a) ve b)'de gösterildiği gibi sürtünme katsayısını içeren ısıl performans katsayısı $(\mathrm{Nu} / \mathrm{f})$ olarak düşünüldüğünde düşük Re sayılarında Model 2 ve Model 5 en iyi performans katsayısı sergilemekte iken Re sayısı arttıkça sürtünme katsayısının azalmasına bağlı olarak Model 1 ve Model 4 için performans katsayısı değerleri artmaktadır. $\mathrm{Bu}$ sonuç, modellerin 1sı transferi performansları değerlendirilirken basınç kaybının da dikkate alınması gerektiğini göstermektedir. 
Daralan ve Genişleyen Bir Kanal İçerisine Yerleştirilen Yarım Küreler Üzerinden Akış ve Isı Transferinin Sayısal Olarak Araștırılması

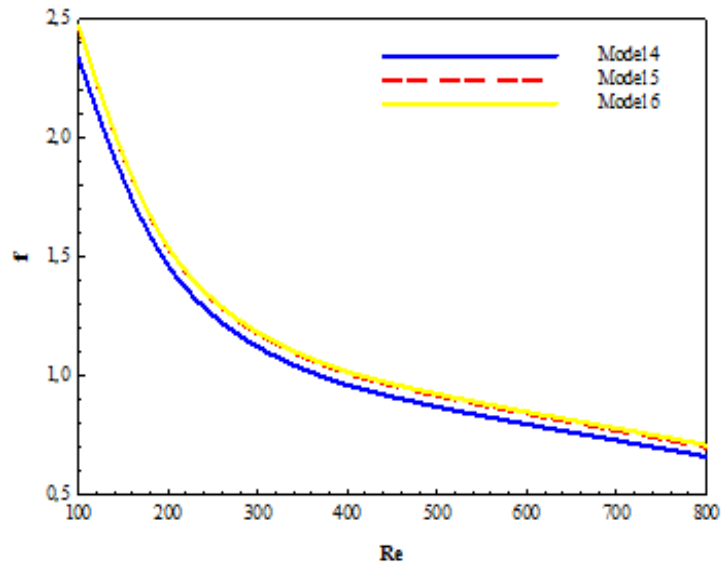

Şekil 9. Basınç kayıp katsayısının (f-sürtünme faktörü) Reynolds sayısı ile değişimi

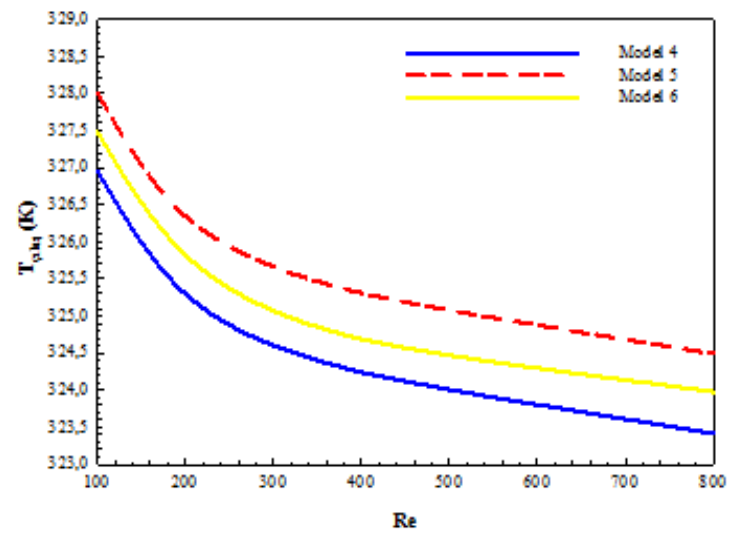

Şekil 10. Akışkan çıkış sıcaklığının Reynolds sayısı ile değişimi

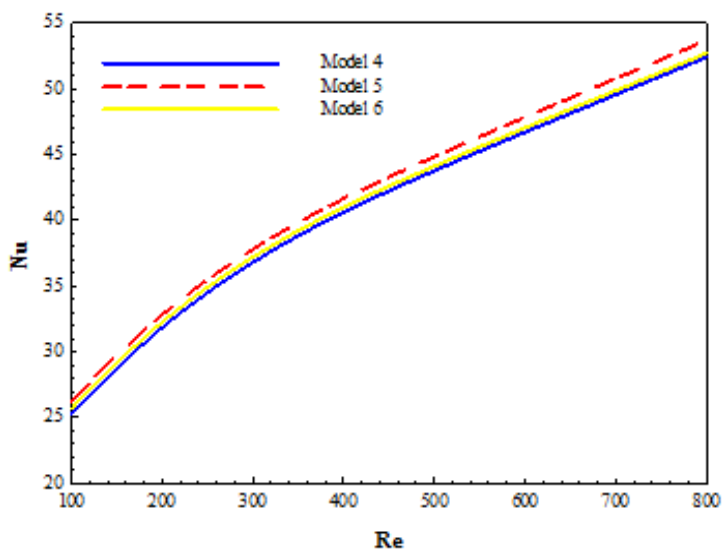

Şekil 11. Kanal boyunca ortalama Nusselt sayısının Reynolds sayısı ile değişimi

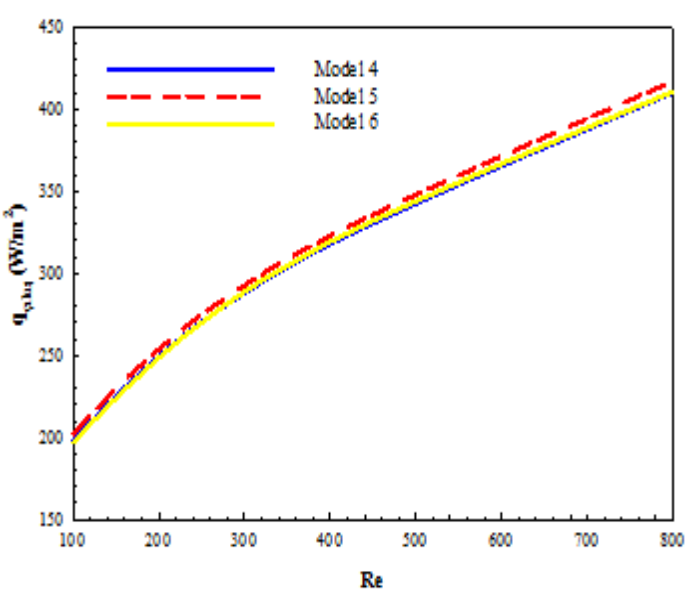

Şekil 12. Kanal çıkışında ısı miktarının Reynolds sayısı ile değişimi
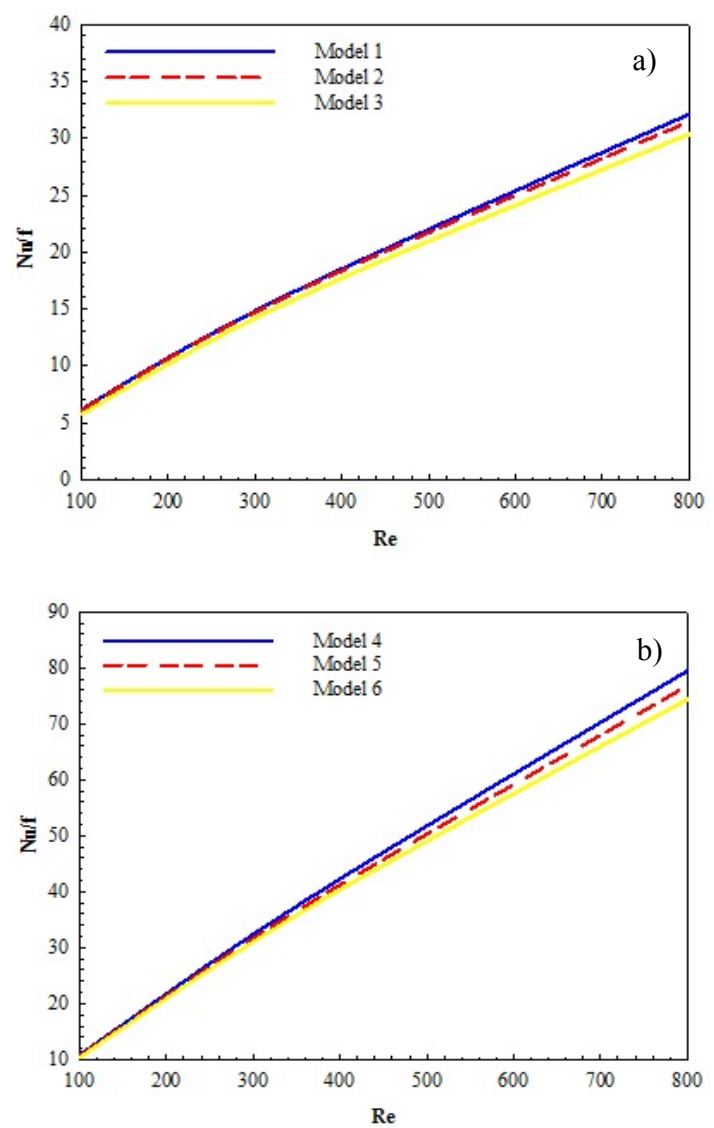

Şekil 13. Isıl performans katsayısının (Nu/f) Reynolds sayısı ile değişimi a) Model 1,2 ve 3 için b) Model 4,5 ve 6 için 
Şekil 14'de Model 4, 5 ve 6 için $R e=100$ 'de akışkanın kanal içerisindeki yarım küreler arasındaki hareketi hız vektörleri kullanılarak görselleştirilmiştir. Ayrıca, üst sıradan başlamak üzere yarım küreler arasındaki akışın daha iyi gösterilebilmesi amacıyla her üç model için de 2 . ve 3. sıradaki küreler yakınlaştırılarak verilmiştir. Model 4 için akış küreler arasındaki kanallardan geçerken yarım küreler etrafindaki hareketi oldukça azdır. Buna karşın, Model 5 için yarım küreler yatayla $20^{\circ}$ 'lik açı yapacak şekilde kanala yerleştirildiklerinden akışkan rahatlıkla küreler arasına yönlendirilmekte ve kürenin alt tarafından gelen akışkanla da karışması sağlanabilmektedir (Şekil 14). Model 6'da ise yarım kürelerin kanala yerleştirilme durumları nedeniyle akışkan kürelerle temasta olmasına rağmen akışkanın hem kürelerin arasındaki hareketi hem de birbiriyle karışımı Model 5'e göre daha güç olmaktadır. Ayrıca, her üç model için Şekil 14'deki hız dağılımı vektörlerinden de görülebileceği gibi kürelerin akışa engel oluşturması nedeniyle kanal boyunca en düşük hız değerlerine küreler arasında ulaşılmaktadır.

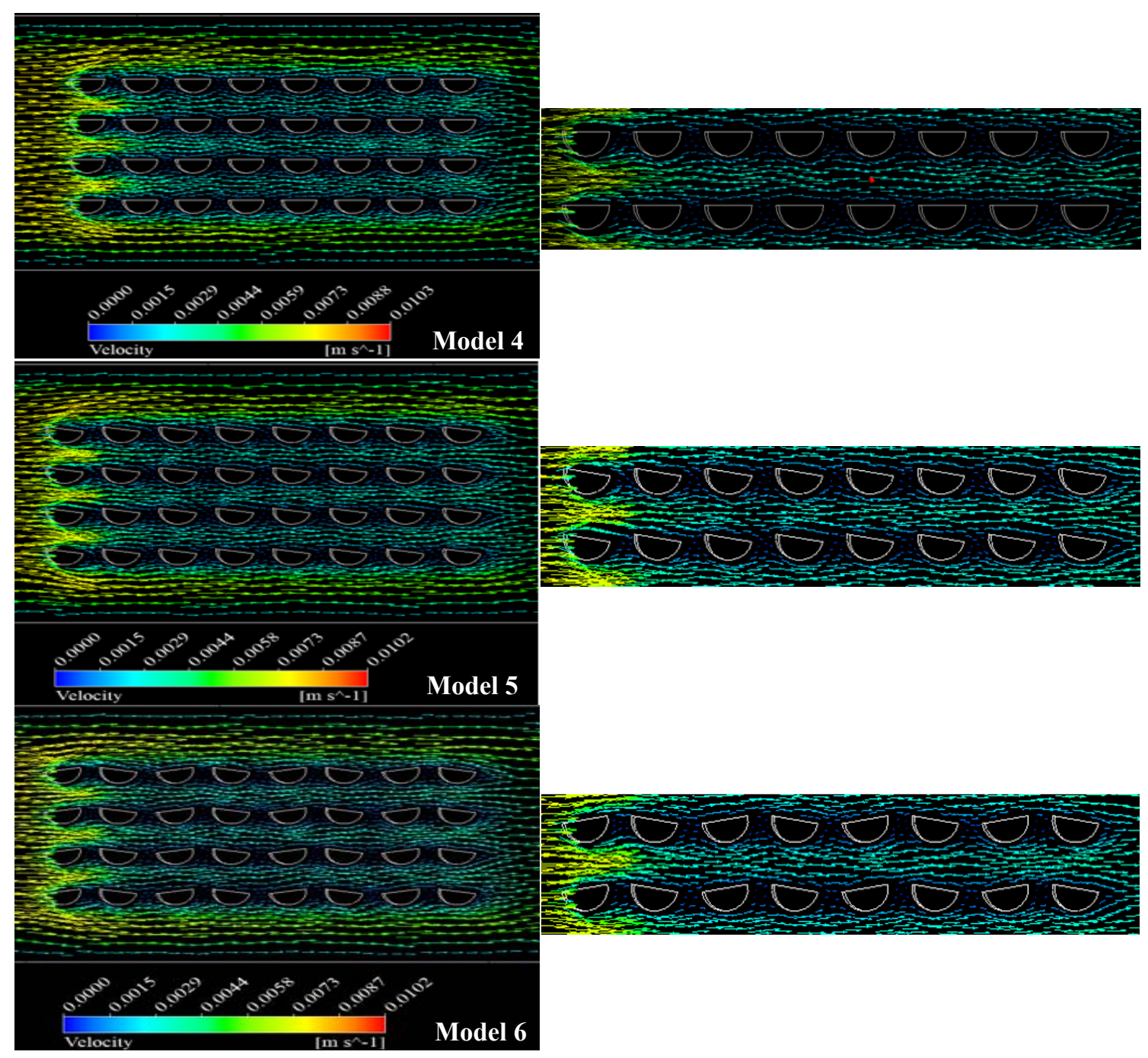

Şekil 14. Model 4, 5 ve 6 için hız vektörlerinin gösterimi, Re=100 
Daralan ve Genişleyen Bir Kanal İçerisine Yerleştirilen Yarım Küreler Üzerinden Akış ve Isı Transferinin Sayısal Olarak Araştırılması

Şekil 15 'de kanala düz olarak yerleştirilmiş 4 sıralı her sirada 8 adet küre olmak üzere toplamda 32 adet yarım küreden oluşan Model 4'e ait daralan genişleyen bir kanaldaki sıcaklık ve hız konturları gösterilmektedir (Şekil 15 A ve B). Küre sayısının artmasıyla kanallar arası akışkan geçişi zorlaştığından düşük Re'da daha sıcak bir akışkan ve kanal bölgesi oluştuğu Şekil 15 A-a)'daki sıcaklık konturu dağılımından görülebilmektedir. Buna bağlı olarak kanallar arası hız değerleri de oldukça azalmaktadır (Şekil 15 A-b). Ancak Re sayısı artırıldığında hız sınır tabakası kalınlığ azalmakta ve bu da kontur dağılımını etkilemektedir (Şekil 15 B- a ve b)).
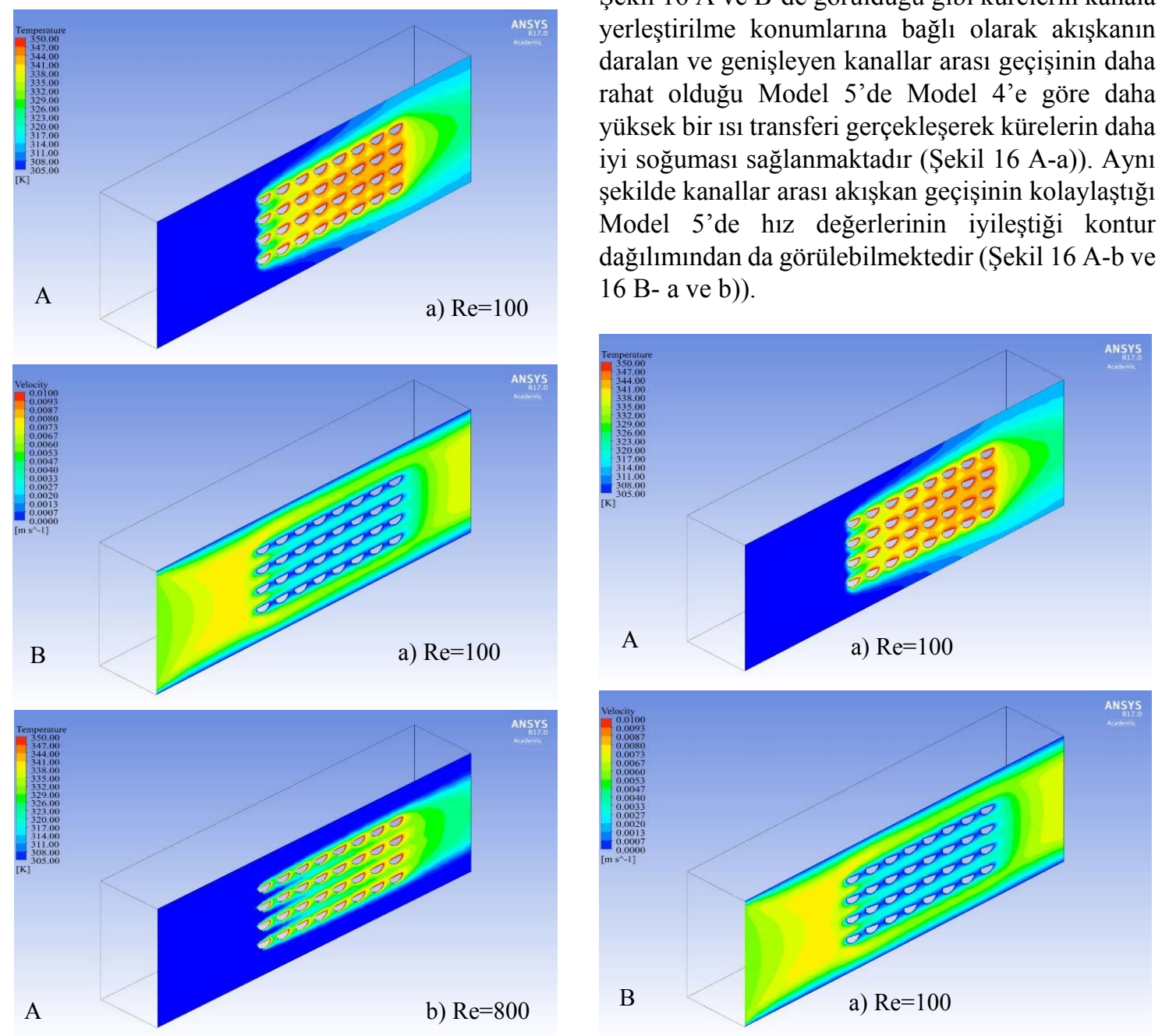

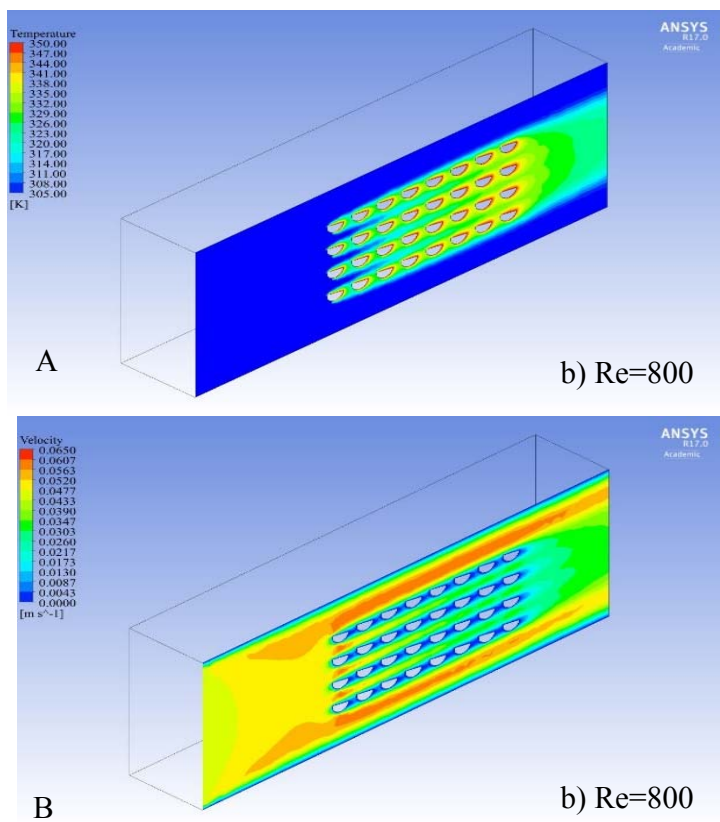

Şekil 16. Model 5 için A-sıcaklık B-hız dağılımı konturlar1

Şekil 17 A ve B'de sırasıyla birbirlerine göre eğimli olarak yerleştirilmiş 32 adet yarım kürenin oluşturduğu daralan genişleyen kanala ait sirasıyla sıcaklık ve hız dağılımları gösterilmektedir. Kanallar arası akışkan hareketinin zorlaşması 1sı transferini de azalttığından özellikle kanalın sonuna doğru küreler arası daha sıcak bir bölgenin oluşmasına sebep olmaktadır (Şekil 17 A-a)). Re sayısının artması 1sı transferini arttırsa da kanalın sonuna doğru akışkan geçişinin de zorlaşmasıyla 1sı transferi azalmaktadır. Buna bağlı olarak da hızın daralan genişleyen kanalın sonuna doğru azaldığ kontur dağılımından görülebilmektedir (Şekil 17 Ba ve b)).

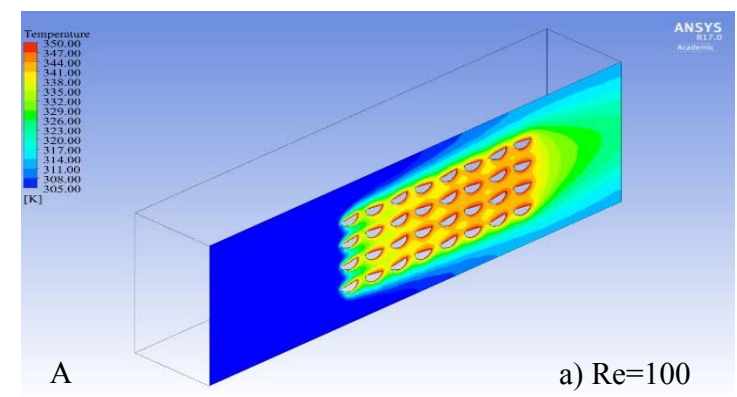

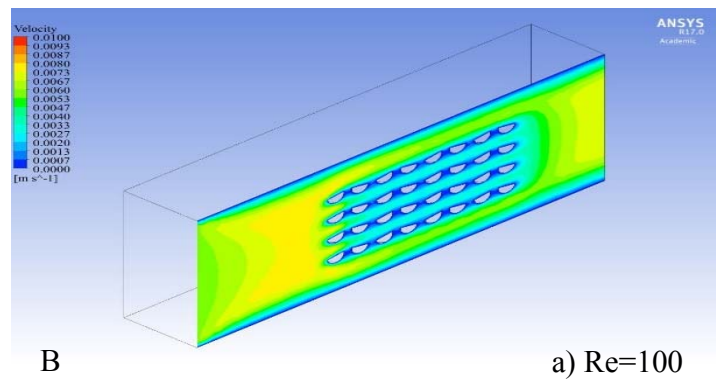
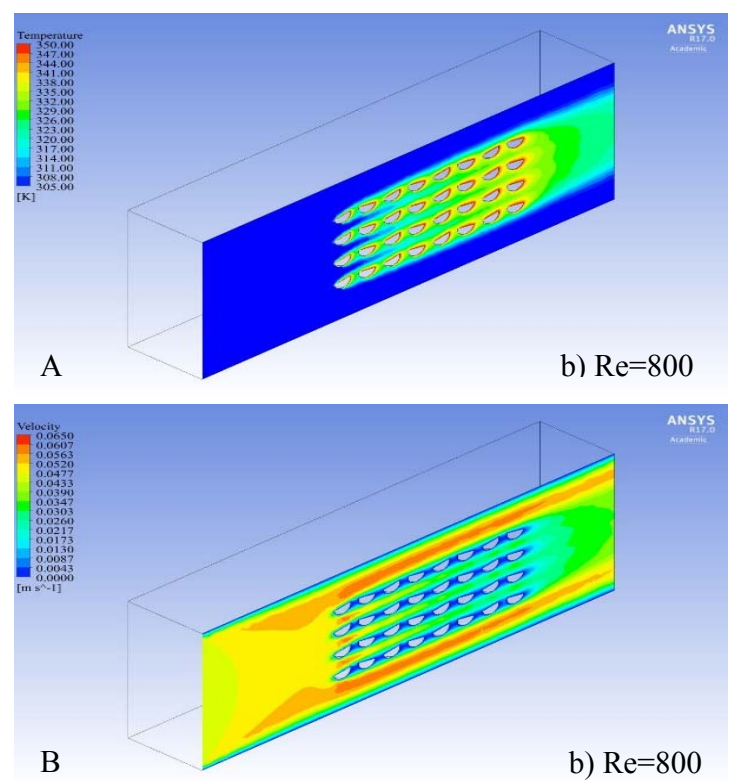

Şekil 17. Model 6 için A-sıcaklık B-hız dağılımı konturlar1

\section{SONUCLAR}

Elektronik ekipmanların fazla isınması sonucu sistemdeki 1sıl gerilmelerin artması ve mekanik arızalar sebebiyle olabilecek istenmeyen sonuçların önlenmesi bakımından etkin bir şekilde soğutulmaları gerekmektedir. Isı transferi yüzey alanının artırılması ve en önemlisi karışım bölgesi oluşturularak ısı transfer katsayısının iyileştirilmesi için geliştirilen yöntemlerden biri, birbirleriyle bağlantılı daralan ve genişleyen kanallardır. Bu kanallar sayesinde birim hacimde yüzey alanı arttırılarak ve özellikle karışım bölgesi oluşturularak 1sı geçişinde iyileştirme yapılabilir. Böylece, hem bilgisayar soğutmasında kullanılan fan gücü azaltılmış olacak hem de işlemcinin 
soğutulması artırılarak bilgisayar performansında iyileşme sağlanabilecektir.

Sunulan bu çalışmada, düz kanala yerleştirilen yarım küre şeklindeki geometrilerle oluşturulan daralan ve genişleyen kanalların isı transferi performans özelliklerini ve basınç düşüşünü araştırmak amacıyla tekli dizilimde 8 adet ve çoklu dizilimde her sırada 8 adet olmak üzere 4 siralı toplamda 32 adet yarım küreden meydana gelen 6 farklı tasarım için yarım kürelerin birbirlerine göre farklı şekillerde yerleşiminin daralan ve genişleyen kanalların ısı transferi, basınç düşüşü ve akış yapısı üzerindeki etkileri üç boyutlu, sıkıştırılamaz, zamana bağlı, tam gelişmiş ve laminer akış için korunum denklemlerinin Ansys Fluent-17.0 bilgisayar programı kullanılarak sayısal olarak çözülmesiyle incelenmiştir. Sayısal çözümde ortalama olarak $140 \mathrm{~s}$ sonra belirtilen yakınsama kriterlerine ulaşıldığından bu zaman süreci bitiminde elde edilen sonuçlar sunulmuştur.

Model 1, 2 ve 3'e ait akışkan kanal çıkış sıcaklıklarının Reynolds sayısı ile değişimi incelendiğinde, akışkanın yarım küreler arasındaki kanallardan geçişinin daha güç olması nedeniyle en yüksek basınç kayıp katsayısı Model 3 için elde edilmiş ( $R e=200$ 'de Model 1 için f değeri 1,1591 iken, Model 2 ve 3 için sırasıyla 1,2635 ve 1,2697) ve akışkan hareketinin daha rahat olduğu Model 2'de Model 3'e göre akışkan çıkış sıcaklığı daha yüksektir. $R e=400$ için Model 2'de çıkış sıcaklık değeri 315,47 K iken Model 3'de 314,96 K olmaktadır. Bununla birlikte, en düşük çıkış sıcaklığı ise karışma miktarının daha az olduğu Model 1'de elde edilmiştir ( $\mathrm{Re}=400$ için $\mathrm{T}=314,46 \mathrm{~K}$ ). Bu nedenle, Model 2 tekli dizilimde 1sı transferinin en iyi olduğu dizilimdir.

Model 4, 5 ve 6 için akışkanın kanaldan çıkış sıcaklığının Re sayısı ile değişimi analiz edildiğinde 1S1 transfer yüzey alanının artırıldığı her üç model içinde Model 5'de diğer modellere göre akışkanın kanallar arasından geçişi de iyileştirildiğinden daha yüksek akışkan çıkış sıcaklık değerine ulaşılmaktadır. Bu değer Re=800'de 324,4898 K değerine ulaşmaktadır. Bununla birlikte, akışkan hızının artırılması taşınımla 1S1 transferini artırdığından $\mathrm{Nu}$ sayısı da artmaktadır. En yüksek $\mathrm{Nu}$ sayısı değerine yine akışkan geçişinin ve karışmanın daha iyi olduğu Model 5'de ulaşılmaktadır ( $\mathrm{Re}=800$ için $\mathrm{Nu}=53,7034)$. $\mathrm{Re}$ sayısının artışı 1Sı transferi miktarını artırırken, en yüksek 1sı transferi miktarına yine Model 5 için ulaşılmaktadır. $\mathrm{Bu}$ değer, $\mathrm{Re}=800$ için $416,9964 \mathrm{~W} / \mathrm{m}^{2}$ dir

Uygulamada 1Sı transferi yanında basınç kayıpları da göz önünde bulundurulması gereken önemli parametrelerden biridir. Çünkü akışkanın kanal içerisinde hareketlendirilerek 1Sı transferinin sağlanması fan kullanılarak gerçekleştirilirken, fan gücü de basınç kayıplarına bağlı olarak artış göstermektedir. Modeller, yalnızca 1S1 transferi bakımından değerlendirildiğinde Model 2 ve Model 5 için en iyi sonuçlar elde edilirken sürtünme faktörünün de dikkate alındığ 1 1Sı transferi performans katsayısı göz önüne alındığında ise özellikle yüksek Re sayılarında sürtünme faktörünün de azalmasıyla Model $1(\mathrm{Re}=800$ için $\phi=32,11)$ ve Model $4(\mathrm{Re}=800$ için $\phi=79,45)$ ön plana çıkmaktadır.

Hız ve sıcaklık konturlarından da görüldüğü gibi Re sayısı arttıkça sınır tabaka kalınlıkları incelmekte ve düşük Re sayılarında görülen kürelerin arkasında sınır tabaka birleşmesi geciktirilmektedir. Aynı zamanda, daralan ve genişleyen kanalların is1 transferini artırma özelliklerinden biri olan sınır tabakanın sürekli yenilenmesi ile kürelerden olan 1s1 transferi artarak kanaldaki akışkana aktarılmaktadır. Bu durum, akışkanın daima yarım küreler ile oluşturulan daralan ve genişleyen kanallar arasına yönlendirilmesiyle sağlanmaktadır. Özellikle, Model 2 ve Model 5'de akışkanın kanallar arasinda daha iyi hareketlenmesi sağlanarak karışma oranı, 1sı transferi yüzey alanı ve dolayısıyla isı transferinde artış elde edilmektedir.

Bununla birlikte, kanallar arası akışkan geçişinin iyi olması ve buna bağlı olarak karışım oranının ve 1sı transferinin artırılması bakımından kürelerin sayısı ve kanala yerleştirilme durumları büyük bir önem arz etmektedir. 


\section{KAYNAKLAR}

1. Sparrow, E.M., Prata, A.T., 1983. Numerical Solutions for Laminar Flow and Heat Transfer in a Periodically Converging-Diverging Tube with Experimental Confirmation, Num. Heat Trans., 6(4), 3219-3230.

2. Patankar, S.V., Liu, C.H., Sparrow, E.M., 1977. The Periodic Thermally Developed in Ducts with Streamwise Periodic Wall Temperature or Heat Flux, Int. J. Heat Mass Trans., 21(5), 557-666.

3. Kelkar, K.M., Patankar, S.V., 1987. Numerical Prediction of Flow and Heat Transfer in a Parallel Plate Channel with Staggered Fins, J. Heat Trans., 109(1), 25-30.

4. Wang, G., Vanka, S.P., 1995. Convective Heat Transfer in Periodic Wavy Passages, Int. J. Heat Mass Trans., 38(17), 3219-3230.

5. Chunhua, M., Chengying, Q., Xiangfei, K., Jiangfeng, D., 2010. Experimental Study of Rectangular Channel with Modified Rectangular Longitudinal Vortex Generators, Int. J. Heat and Mass Trans., 53(15-16), 3023-3029.

6. Pankaj, S., Gautm, B., Subrata, S., 2014. Comparision of Winglet-Type Vortex Generators Periodically Deployed in a Plate-Fin Heat Exchanger-A Synergy Based Analysis, Int. J. Heat Mass Trans., 74, 292-305.

7. Zhu, J.X., Fiebig, M., Mitra, N.K., 1995. Numerical Investigation of Turbulent Flows and Heat Transfer in a Rib-Roughed Channel with Longitudinal Vortex Generators, Int. J. Heat Mass Trans., 38(3), 495-501.

8. Chunhua, M., Chengying, Q., Enyu, W., Liting, T., Yaju, Q., 2012. Numerical Investigation of Turbulent Flow and Heat Transfer in a Channel with Novel Longitudinal Vortex Generators, 55 (23-24), 7268-7277.

9. Sohankar, A., 2007. Heat Transfer Augmentation in a Rectangular Channel with Vee-Shaped Vortex Generator, Int. J. Heat Fluid Flow, 28(2), 306-317.

10. Yilmaz, T., 1982. Numerical Solutions of Navier-Stokes Equations for Laminar Flow in Rows of Plates in Staggered Arrangement, Int. Heat Fluid Flow, 3(4), 201-206.
11. Yilmaz, T., Ayhan, T., 1983. Birbirleriyle Bağlantılı Daralan ve Genişleyen Kanallarda Isı Transferi, 4. Ulusal Isı Bilimi ve Tekniği Kongresi.

12. Erdinc, M.T., Yllmaz, T., 2018. Numerical Investigation of Flow and Heat Transfer in Communicating Converging and Diverging Channels, Journal of Thermal Engineering, 4(5), 2318-2332.

13. Xu, F., Zhong, S., Zhang, S.Y., 2018. Vortical Structures and Development of Laminar Flow Over Convergent-Divergent Riblets, Physics of Fluids, 30(5), 10.1063/1.5027522.

14. Fuji, M., Sensimo, Y., Yamanaka, G., 1988. Heat Transfer and Pressure Drop of Perforated Surface Heat Excganger with Pasage Enlargement and Contraction, Int. Heat Mass Trans., 31(1), 135-142.

15. Kotcioğlu, I., Bölükbaş1, A., 2003. Düşey Dikdörtgen Kesitli Bir Kanalda Farklı Kanatçıklı Yüzeylerde Isı Transferinin İncelenmesi, D.E.Ü. Müh. Fak. Fen ve Müh. Dergisi, 5(2), 89-102.

16. Karabulut, K., Alnak, D.E., Koca, F., Özalp, C., 2018. Numerical Analysis of Flow and Heat Transfer for Semi Spheres Placed as Multiple Serials in a Channel, European Mechanical Science, 2(3), 76-82.

17. FLUENT User's Guide, 2003. Fluent Inc. Lebanon, NH.

18. Erdinc, M.T., 2014. Birbirleriyle Bağlantılı Daralan ve Genişleyen Kanallarda Akış ve Isı Geçişinin Sayısal Olarak İncelenmesi, Yüksek Lisans Tezi, Osmaniye Korkut Ata Üniversitesi, Fen Bilimleri Enstitüsü. 
